\title{
In silico study of baicalin as an inhibitor of HER-2 receptor in breast cancer
}

\author{
Kadek Adi Arya Wiranata $\mathbb{D}^{*}$, Made Agus Widiana Saputra $\mathbb{D}$, Ni Kadek Diah Parwati Dewi $\mathbb{D}$, \\ Ni Ketut Nitya Cahyani (D)
}

Department of Pharmacy, Faculty of Mathematics and Natural Science, Udayana University, Bukit Jimbaran, Badung, Bali 80361, Indonesia

"Corresponding author: Jl. Kampus Bukit Jimbaran, Udayana University, Badung, Bali 80361, Indonesia. Email: adiaryaw@gmail.com

\begin{abstract}
Breast cancer is the second cause of female death in the world. Lapatinib targeting HER-2 is the common inhibitor for breast cancer therapy. This study reports the potential of baicalin as an inhibitor of HER-2 through in silico molecular docking. The study was conducted by structure optimization of baicalin and lapatinib, preparation of HER-2 (PDB ID: 3PP0) target protein, validation of the molecular docking method, and docking of baicalin and lapatinib. The results showed that baicalin had an affinity for HER-2 with a binding energy of $-6.0 \mathrm{kcal} / \mathrm{mol}$, while the binding energy of the $03 \mathrm{Q}$ native ligand and lapatinib to HER-2 was $-4.79 \mathrm{kcal} / \mathrm{mol}$ and $-3.98 \mathrm{kcal} / \mathrm{mol}$, respectively. This finding indicated that baicalin is a potential breast anticancer through the inhibition of the HER-2 protein.
\end{abstract}

Keywords: baicalin, breast cancer, HER-2, lapatinib, molecular docking

\section{Introduction}

Breast cancer is the second leading cause of cancer death in women, with approximately 25\% of breast cancers classified as HER-2 positive [1]. Human epidermal growth factor receptor 2 (HER2) is overexpressed in $20-30 \%$ of breast cancer tumors [2]. Treatment of breast cancer depends on the size of the lesion, hormone receptivity and histologic markers, presence or absence of metastatic or contralateral disease, and patient age. HER2-targeted therapies are an important advance in breast cancer treatment. Lapatinib, a tyrosine kinase inhibitor that targets HER-2, is a drug used for breast cancer therapy [3]. Signaling through other ErbB/HER RTKs can transactivate HER2 and amplify signal transduction downstream, thus bypassing the inhibitory effect of lapatinib [4].

Another strategy to find treatment for HER-2 overexpression breast cancer is exploring the natural ingredients to be developed into pharmaceutical products. Baicalin is the most abundant flavonoid glycoside found in Scutellaria baicalensis species [5]. Baicalin induces the oxidative degradation of DNA and proteins that lead to the death of MCF-7 cells [6]. Baicalin can inhibit the metastasis of breast cancer by inhibiting the migration and invasion of the breast cancer cell lines MDA-MB-231 and 4T1 [7].
A preliminary test by in silico molecular docking of baicalin in inhibiting HER-2 receptor overexpression is required. This method can predict the interaction between the molecule and protein [8]. Therefore, this study aims to study the potential effect of baicalin to inhibit HER-2 activity using the molecular docking method.

\section{Methods}

The molecular docking study of baicalin and lapatinib was performed as previously reported $[9,10]$. Briefly, baicalin and lapatinib structures were obtained from https://pubchem.ncbi.nlm.nih.gov/ and optimized using HyperChem 8.The HER-2 protein (PDB ID: 3PP0) containing 03Q native ligand was retrieved from http://www.rcsb.org and they were separated by Chimera 1.10.1.The grid box size and grid center coordinate for validation of the docking protocol and baicalin and lapatinib docking were refer to Putra et al. [10].

\section{Results}

The single-point calculation and geometric optimization energies of baicalin compounds were $-5208.21 \mathrm{kcal} / \mathrm{mol}$ and $-6596.2147 \mathrm{kcal} / \mathrm{mol}$, while for lapatinib were $-8781.79 \mathrm{kcal} / \mathrm{mol}$ and -8860.12 
a

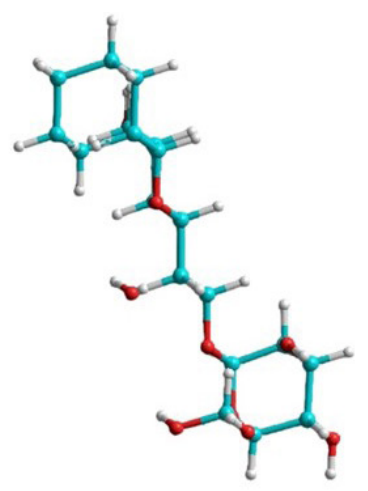

c

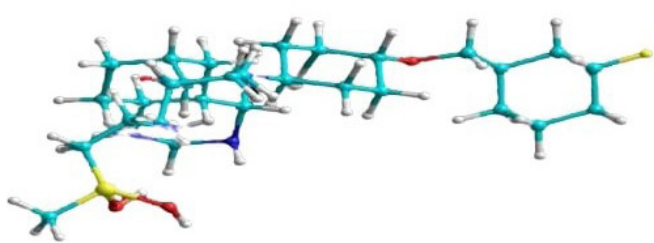

b

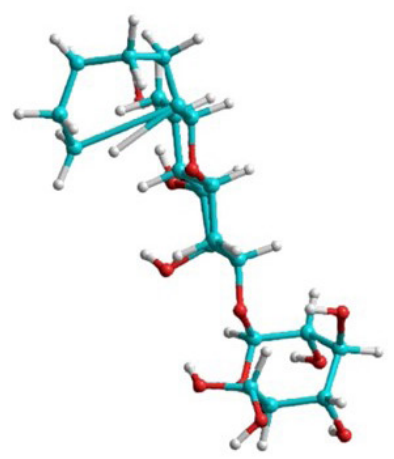

d

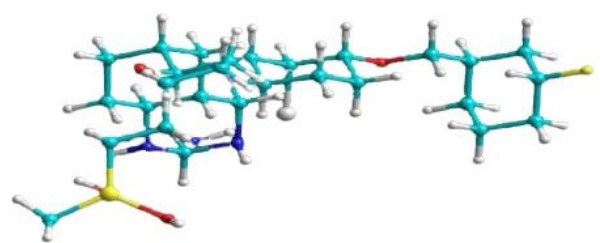

Figure 1. The 3D structures of optimized baicalin and lapatinib. (a) single point calculation of baicalin, (b) geometry optimization of baicalin, (c) single point calculation of lapatinib, (d) geometry optimization of lapatinib

a

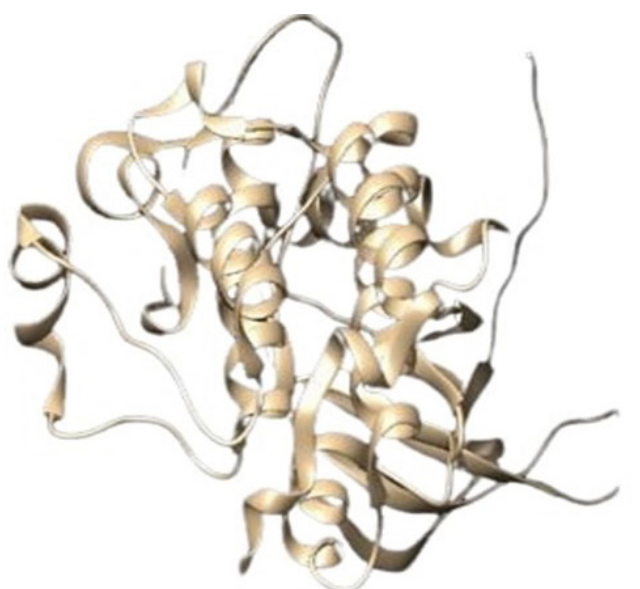

b

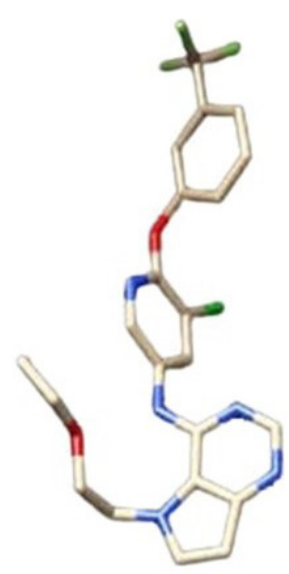

Figure 2. The results of protein preparation. (a) HER-2 protein without native ligand, (b) $03 \mathrm{Q}$ native ligand

$\mathrm{kcal} / \mathrm{mol}$. The 3D structures of optimized baicalin and lapatinib are shown in Figure 1. HER-2 protein preparation involved the separation of protein from 03Q native ligand. The prepared protein and the obtained 03Q native ligand were displayed in Figure 2. The validation of docking process produced ten conformations of $03 \mathrm{Q}$ native ligand which the lowest RMSD value was $0.47 \AA$ (Table 1).

Docking of baicalin and lapatinib to HER-2 protein resulted in ten conformations with the lowest binding energy of baicalin and lapatinib were $-6.21 \mathrm{kcal} / \mathrm{mol}$ and $-12,19 \mathrm{kcal} / \mathrm{mol}$ (Table 2 and 3). The 03Q native ligand, lapatinib, and baicalin interacted to HER-2 through hydrogen bonding. The $03 \mathrm{Q}$ native ligand and lapatinib associated to HER-2 through MET 801 residue, while baicalin through LYS 753 residue (Figure 3).

\section{Discussion}

Our results showed that baicalin has the energy binding of $-6.21 \mathrm{kcal} / \mathrm{mol}$, while the binding energy of $03 \mathrm{Q}$ native ligand and lapatinib were $-10.47 \mathrm{kcal} / \mathrm{mol}$ and $-12.19 \mathrm{kcal} / \mathrm{mol}$, respectively. The negative value of the binding energy indicates the affinity between the test compounds with the target protein. The lower the binding energy, the stronger the interaction formed [11]. 
a

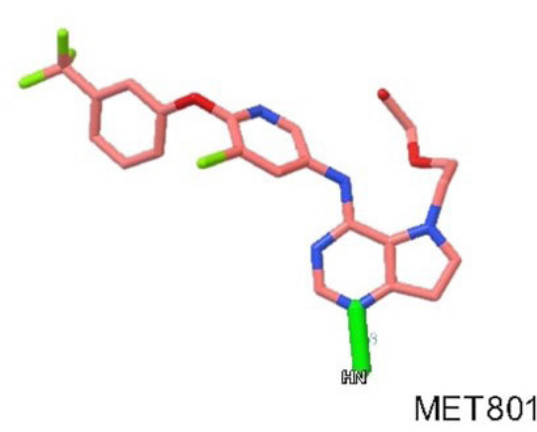

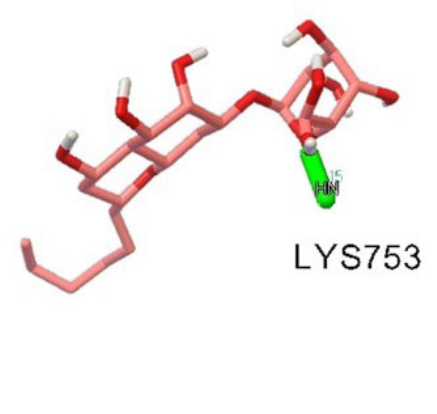

C

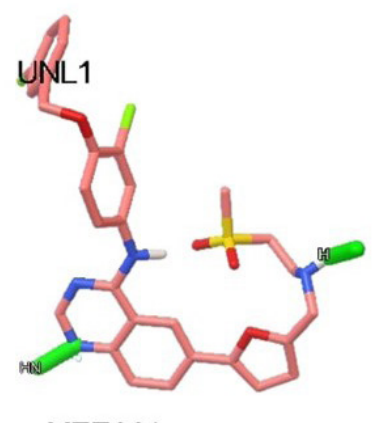

MET 801

Figure 3. Visualization interaction of docking results. (a) $03 \mathrm{Q}$ native ligand, (b) baicalin, (c) lapatinib

Table 1. The result of redocking $03 \mathrm{Q}$ on HER-2

\begin{tabular}{cccccc}
\hline Ligand & Conformations & $\begin{array}{c}\text { RMSD } \\
(\mathbf{A})\end{array}$ & $\begin{array}{c}\text { Binding } \\
\text { energy } \\
\text { (kcal/mol) }\end{array}$ & $\begin{array}{c}\text { Amino acid } \\
\text { residues }\end{array}$ & $\begin{array}{c}\text { Groups in } \\
\text { hydrogen } \\
\text { bonds }\end{array}$ \\
\hline 1 & 1.69 & -10.01 & MET 801 & HN-N11 \\
& 2 & 3.13 & -9.47 & MET 801 & HN-O1 \\
& $3^{*}$ & 0.47 & -10.47 & MET 801 & HN-N11 \\
& 4 & 5.63 & -7.52 & - & - \\
O3Q & 2.58 & -7.60 & THR 862 & HG1-N18 \\
& 6 & 1.73 & -10.05 & MET 801 & \\
& 7 & 0.74 & $-9,92$ & HN-N11 & HN-N11 \\
& 8 & 3.02 & -9.14 & MET 801 & HN-N18 \\
\hline
\end{tabular}

Table 2. The result of molecular docking of baicalin on HER-2

\begin{tabular}{ccccc}
\hline Ligand & Conformations & $\begin{array}{c}\text { Binding energy } \\
\text { (kcal/mol) }\end{array}$ & $\begin{array}{c}\text { Amino acid } \\
\text { residues }\end{array}$ & $\begin{array}{c}\text { Groups in } \\
\text { hydrogen bonds }\end{array}$ \\
\hline 1 & -4.72 & THR 862 & HG1 \\
2 & -4.94 & - & - \\
3 & -4.77 & - & - \\
4 & -5.91 & - & - \\
Baicalin & -5.66 & - & - \\
& 6 & -4.39 & - & HN-O \\
& 7 & -5.57 & ASP 863 & HN-O \\
& $8^{*}$ & -6.21 & LYS 753 & - \\
9 & -5.03 & THR 862 & HG1-O \\
\hline
\end{tabular}

In vitro studies on the anti-breast cancer activity of baicalin were assessed in MCF-7 breast cancer cells. The result demonstrated that 20 and $30 \mu \mathrm{M}$ baicalin reduced cell proliferation in 48 and 72 hours, indicating that this compound inhibits cell proliferation [12]. Baicalin also showed a significant effect on migration and invasion suppression in highly aggressive breast cancer metastases both in vitro and in vivo, via reversal of the 
Table 3. The result of molecular docking of lapatinib on HER-2

\begin{tabular}{ccccc}
\hline Ligand & Conformations & $\begin{array}{c}\text { Binding Energy } \\
\text { (kcal/mol) }\end{array}$ & $\begin{array}{c}\text { Amino acid } \\
\text { residues }\end{array}$ & $\begin{array}{c}\text { Groups in } \\
\text { hydrogen bonds }\end{array}$ \\
\hline 1 & -10.91 & MET 801 & HN-N \\
2 & -11.69 & MET 801 & HN-N \\
$3^{*}$ & -12.19 & MET 801 & HN-N \\
4 & -11.58 & MET 801 & HN-N \\
Lapatinib & +4.56 & - & HN-N \\
& 6 & -11.22 & MET 801 & HN-N \\
& 7 & -11.20 & MET 801 & HN-N \\
8 & -8.87 & MET 801 & HN-N \\
9 & -7.45 & MET 801 & HN-N \\
\hline
\end{tabular}

epithelial-to-mesenchymal transition (EMT) process and downregulation of $\beta$-catenin expression [7]. In addition, baicalein inhibits the metastatic phenotypes of nasopharyngeal carcinoma cells by modulating integrin $\beta 8$ [13]. Baicalein, a baicalin-like compound, has been reported to have anti-breast cancer activity in MCF-7 cells by inhibiting cell proliferation due to cytoskeletal alteration [14]. In silico molecular docking study of quercetin against HER-2 protein yielded a binding energy value of $-8.24 \mathrm{kcal} / \mathrm{mol}$ [15].

\section{Conclusion}

Baicalin has a potential as an HER-2 protein inhibitor which benefits to be developed in breast cancer therapy.

\section{Acknowledgment}

None.

\section{Declaration of interest}

The authors declare no competing interests

\section{Author contributions}

KAAW and NKNC conceptualized the study design, KAAW and MAWS investigated the data, KAAW, MAWS, NKNC, and NKDPD wrote original draft, KAAW, MAWS, NKDPD reviewed and edited final version, KAAW looked for the funding, KAAW supervised all experiments. All authors have read the final manuscript.

Received: 29 December 2021

Accepted: 16 January 2022

Published online: 30 January 2022

\section{References}

1. Callahan R, Hurvitz S. Human epidermal growth factor receptor-2-positive breast cancer: Current management of early, advanced, and recurrent disease. Curr Opin Obstet Gynecol. 2011;23: 37-43. https://doi.org/10.1097/ GCO.0b013e3283414e87

2. Mitri Z, Constantine T, O'Regan R. The HER2 receptor in breast cancer: pathophysiology, clinical use, and new advances in therapy. Chemother Res Pract. 2012;2012: 743193. https://doi.org/10.1155/2012/743193

3. D'Amato V, Raimondo L, Formisano L, Giuliano M, De Placido S, Rosa R, et al. Mechanisms of lapatinib resistance in HER2-driven breast cancer. Cancer Treat Rev. 2015;41: 877-883. https://doi.org/10.1016/j.ctrv.2015.08.001

4. Watkins EJ. Overview of breast cancer. JAAPA. 2019;32: 1317. https://doi.org/10.1097/01.JAA.0000580524.95733.3d

5. Wang Z-L, Wang S, Kuang Y, Hu Z-M, Qiao X, Ye M. A comprehensive review on phytochemistry, pharmacology, and flavonoid biosynthesis of Scutellaria baicalensis. Pharm Biol. 2018;56: 465-484. https://doi.org/10.1080/13 880209.2018.1492620

6. Liu Z-H, Yang C-X, Zhang L, Yang C-Y, Xu X-Q. Baicalein, as a Prooxidant, Triggers Mitochondrial Apoptosis in MCF-7 Human Breast Cancer Cells Through Mobilization of Intracellular Copper and Reactive Oxygen Species Generation. Onco Targets Ther. 2019;12: 1074910761. https://doi.org/10.2147/OTT.S222819

7. Zhou T, Zhang A, Kuang G, Gong X, Jiang R, Lin D, et al. Baicalin inhibits the metastasis of highly aggressive breast cancer cells by reversing epithelial-to-mesenchymal transition by targeting $\beta$-catenin signaling. Oncol Rep. 2017;38: 3599-3607. https://doi.org/10.3892/or.2017.6011

8. Lin X, Li X, Lin X. A review on applications of computational methods in drug screening and design. Molecules. 2020;25. https://doi.org/10.3390/molecules25061375

9. Cahyani NKN, Putri WNE, Dwiivayana IKD, Mirayanti NPD, Laksmiani NPLL. In silico study of lutein as antiHER-2 receptors in breast cancer treatment. PharmRep. 2021;1: 17. https://doi.org/10.51511/pr.17 
10. Putra IMH, Pratama IPAAC, Putra KDA, Pradnyaswari GAD, Laksmiani NPL. The potency of alpha-humulene as HER-2 inhibitor by molecular docking. PharmRep. 2022;2: 19. https://doi.org/10.51511/pr.19

11. Du X, Li Y, Xia Y-L, Ai S-M, Liang J, Sang P, et al. Insights into Protein-Ligand Interactions: Mechanisms, Models, and Methods. Int J Mol Sci. 2016;17. https://doi. org/10.3390/ijms17020144

12. Gao Y, Liu H, Wang $\mathrm{H}, \mathrm{Hu} \mathrm{H}, \mathrm{He} \mathrm{H}, \mathrm{Gu}$ N, et al. Baicalin inhibits breast cancer development via inhibiting IкB kinase activation in vitro and in vivo. Int J Oncol. 2018;53: 2727-2736. https://doi.org/10.3892/ijo.2018.4594
13. Kiatwuthinon P, Narkthong T, Ngaokrajang U, Kumkate S, Janvilisri T. Baicalein inhibits metastatic phenotypes in nasopharyngeal carcinoma cells via a focal adhesion protein integrin $\beta 8$. Pharmaceuticals (Basel). 2021;15. https://doi. org/10.3390/ph15010005

14. Topçul MR. Evaluation of kinetic effects of baicalein in different breast cancer cell lines. CSJ. 2019;40: 150157. https://doi.org/10.17776/csj.511141

15. Rastini MBO, Giantari NKM, Adnyani KD, Laksmiani NPL. Molecular docking aktivitas antikanker dari kuersetin terhadap kanker payudara secara in silico. Jurnal Kimia. 2019; 180. https://doi.org/10.24843/JCHEM.2019.v13.i02.p09 